\title{
General Discussion to the Papers of Dr Keane, Mrs Rogers and Dr E. McClemont et al.
}

Dr D. Cheshire (Chairman). I would ask you to refrain from paperettes to let discussion commence on four papers delivered this morning so far.

SIR LUDWIG GutTMANN (G.B.). I was interested in that paper of Dr Keane (already published in the February issue). He quite rightly shows concern of the hazards of lifting and turning cervical patients by hand, and I was pleased to see his findings, although it is well known to any neurosurgeon how dangerous the turning by hand is. That was the reason why we introduced the Egerton-Stoke Mandeville turning and tilting bed to relieve the strain on the nursing staff and obviate the manual lifting and turning by three to four members of the nursing staff which was necessary in my method of postural reduction and regular turning every $2-3$ hours day and night. The turning from the supine into the lateral position is now done electrically by just pressing a button, thus allowing the cleaning of the patient and changing the linen. For reduction and stabilising of cervical fractures and the regular turning of the tetraplegic I introduced a special skull traction unit whereby the patient can be turned without removing the traction and the weight. I was, therefore, very surprised to see in one of Mrs Rogers' slides of a tetraplegic, that the patient was lifted by several people with the head traction off and the wrong position of the head in this patient by faulty holding by the person concerned. I consider this kind of method as a regular nursing procedure a grave error as it makes a farce of the electrically controlled turning bed. Cleaning and bowel evacuation can, as a rule, certainly be done when the patient is placed into lateral position by the electrically controlled turning. If in exceptional circumstances lifting of the patient is necessary this must be done properly as described in Mrs Rogers' paper but not as shown in that slide.

With regard to the introduction of a number of other special beds (mud bed etc.) to prevent pressure sores, I like to stress that unless the patient is turned regularly they are of little use in spinal cord injuries. The regular turning of the patient, in particular in the early stages, is not only to prevent pressure but in the first place to avoid prolonged recumbency with its deleterious effects on the urinary tract producing ascending infection of the bladder and stone formation; furthermore, to overcome the disturbed vaso-motor control.

Chairman: Thank you Sir Ludwig.

DR P. Dollfus (France). I would like to ask Phillip Harris if he knows how much his contraption costs in Scotland. Could he give us an idea of the price?

DR P. HARRIS (G.B.). I think it costs $£ \mathrm{I} 60$ here. It is being made commercially now by a firm, I think, in Dundee and it costs about $£$ Ioo.

Dr Sussman (U.S.A.). I would like to echo Dr Guttmann's suggestion that it is hard to justify lifting the patient to a discontinuance of traction, but I think we are overestimating the amount of variation that actually occurred during those turnings and liftings of the patients. I think if you start with a base of $25 \mathrm{lb}$ traction on a patient's head one never has $25 \mathrm{lb}$ of traction on the cervical spine because there is the counter pull of the patient's cervical musculature, there is the friction of the head on the sheet, there is the friction on varying surfaces and, in addition, there are the simple kinetics of the downward weight of the patient's head whatever it may weigh, so certainly there are variations but I doubt very much that they are in the range which is suggested by those figures.

Chairman. Dr Keane must have the right to reply. Dr Keane would you be kind enough to use the microphone behind you and to your left.

DR KEANE (G.B.). I can assure you that quite an amount does take place at the fracture because we've had Ring tree tufts, one not just completed. We have done a light tracing test where we place lights on the patient's forehead, chin, manubrium and so on, 
turn the patient manually and this demonstrates that in fact you do have quite an amount of malalignment during lift and turn, but certainly you can prove this for yourself by simply X-raying the patient's neck when he is in the air and I would suggest that we should do this and in the unstable fracture you will see displacement etc. taking place, certainly in some of the cases.

Chairman. Or perhaps, Dr Keane, one might even do better and not lift the patient in the air at all for the purpose of X-raying his neck.

DR KEANE. May I make another point. I think the problem of pressure sores persists because we have ignored some interesting, though inadvertent, experiments that have been carried out in history. One is the Nazi concentration camps, and it is very interesting to read in the British Medical fournal that the first doctors into Belsen camp described nearly all the complications of hunger disease which have an amazing number of sequalae etc. and there is no mention of decubitae. There was a tremendous effort made by the British Army and within 3 weeks they had set up I 7000 beds for the treatment of these internees. The next papers appeared in the B.M.f. about 3 weeks later and the unique thing was that all the patients had now got large decubita. So the very fact that they took them off the natural support surface for any terrestrial element, namely the ground, and put them on to an artificial surface, namely a man-made surface, a bed, disturbed the function of their bony prominences, made it almost impossible for them to move, and secondly threw the load onto the muscle which is not intended to take pressure. This consequently set up now an ischaemic situation in the muscle. Muscle can only put up with 22 minutes of ischaemia and then cellular damage is evident on microscopic examination and consequently if those subjects had not moved themselves with physiological frequency, which I believe is once every I I times 6 minutes they were destined to develop decubitae.

Chairman. Thank you very much indeed, Dr Keane. One last question, $\mathrm{Mr}$ Griffiths is already recognised.

Mr E. GRIFfiTHS (Australia). The question of the healing of pressure ulcers is not difficult if you have good nursing and good medical management. I think we all know this when we get them into our wards from other hospitals. We can always heal them with good treatment, that's not difficult. The problem is to prevent them occurring in our patients-the ordinary working paraplegic, the working tetraplegic-after discharge. To do this we now have a pressure clinic to measure the pressure on each patient before fitting him with a wheelchair in the first instance, to measure the pressure points over the ischium, the sacrum, the trochanters in sitting in a wheelchair, to prepare a specially sculptured cushion or produce a wheelchair tailored to fit the patient. A sculptured cushion in a clinic prepared by a bio-engineer and a trained nurse measuring the pressure points on that particular patient and reducing pressure on the salient points. And if you do this, we found over the last 2 to 3 years we have reduced our readmission rate for pressure ulcers by about 40 per cent so far, and I am sure we shall go on reducing it by special attention to the seating position and reducing pressure over the difficult points in these patients.

DR H. Frankel (G.B.). I'd just like to reassure Sir Ludwig that we recognise how to use the Egerton bed, and that it does eliminate the vast majority of lifting. It does not, however, eliminate it altogether. There are occasions when the patient has to be lifted and, when they are lifted, the photographs we have shown you are naturally an exaggeration of the height to which the patient is lifted because that's not necessary, that's to demonstrate the position of the hands of our orderlies, but unfortunately we have not yet found a way of nursing a patient for 6 to 8 weeks without lifting him.

SIR LUDWIG (intervening). This was certainly possible previously. 